\title{
Efficacy and safety analysis of dexamethasone-lipiodol emulsion in prevention of post-embolization syndrome after TACE: a retrospective analysis
}

Haohao Lu ${ }^{1,2}$, Chuansheng Zheng ${ }^{1,2^{*}}$, Bin Liang ${ }^{1,2}$ and Bin Xiong ${ }^{1,2}$

\begin{abstract}
Background: To investigate the efficacy and safety of dexamethasone-lipiodol emulsion in the prevention of postembolization syndrome after TACE.

Method: The data of 255 patients who underwent TACE in the interventional department from June 2017 to June 2020 were collected. This is a retrospective assessment of patients who were non-randomly treated with dexamethasone in TACE. The patients were divided into two groups: TACE using lipiodol + chemotherapeutic emulsion group (TACE group, $\mathrm{N}=133$ ); TACE using lipiodol + dexamethasone + chemotherapeutic emulsion group (TACE + dexamethasone group, $\mathrm{N}=122$ ). Primary study endpoint: incidence of abdominal pain, fever, nausea and vomiting $0-72 \mathrm{~h}$ after TACE in both groups. Secondary study endpoints: incidence of infection after TACE in both groups.

Results: Incidence of post-embolization syndrome after TACE (TACE group vs TACE + dexamethasone group): abdominal pain, $55.6 \%$ versus $36.1 \%$ ( $P$ value 0.002 ); fever, $37.6 \%$ versus $13.1 \%$ ( $P$ value 0.000 ); nausea, $60.9 \%$ versus 41.0\% ( $P$ value 0.001 ); vomiting, $48.1 \%$ versus $21.3 \%$ ( $P$ value 0.000 ). Incidence of infection after TACE (TACE group vs TACE + dexamethasone group): $1.5 \%$ versus $2.5 \%$ ( $P$ value 0.583 ).

Conclusion: The lipiodol + dexamethasone emulsion can significantly reduce the incidence rate of post-embolization syndrome after TACE, with exact effect and high safety.

Keywords: Dexamethasone, Lipiodol emulsion, Post-embolization syndrome, TACE, Transarterial chemoembolization, Hepatocellular carcinoma
\end{abstract}

\section{Introduction}

Primary hepatocellular carcinoma is one of the malignant tumors with high morbidity and mortality worldwide [1-3], which is a serious threat to people's life and health. Because there are no obvious specific symptoms and signs in the early stage of the disease, most patients

\footnotetext{
*Correspondence: 1354039648@qq.com

${ }^{1}$ Department of Radiology, Wuhan Union Hospital, Tongji Medical College, Huazhong University of Science and Technology, Jiefang Avenue \#1277, Wuhan 430022, China

Full list of author information is available at the end of the article
}

are found in the middle and advanced stages and lose the chance of surgery. Transcatheter arterial chemoembolization (TACE), It has been performed since the late 1970s $[4,5]$. TACE is currently one of the effective means of treating advanced hepatocellular carcinoma, which significantly prolongs the OS and PFS of patients and benefits an increasing number of patients with hepatocellular carcinoma [6, 7]. The most common side effects after TACE are post-embolization syndrome $[8,9]$, including abdominal pain, fever, nausea and vomiting. Post-embolization syndrome will increase the suffering of 
patients, aggravate the physical and psychological burden of patients and reduce the compliance of patients with treatment. At the same time, it prolongs the patient's hospital stay and increases the patient's medical costs [10]. Because patients with hepatocellular carcinoma are mostly complicated with liver cirrhosis, many patients are complicated with gastric esophageal varices, severe post-embolization syndrome, especially nausea and vomiting, which may lead to gastrointestinal bleeding caused by gastric esophageal varices rupture, and even lead to death of patients. Therefore, prevention of post-embolic syndrome appears crucial. The aim of this study was to investigate the efficacy and safety of dexamethasonelipiodol emulsion in the prevention of post-embolization syndrome after TACE.

\section{Materials and methods}

\section{General information}

The data of 255 patients who underwent TACE in the Department of Intervention, Wuhan Union Hospital, Tongji Medical College, Huazhong University of Science and Technology from June 2017 to June 2020 were collected. Inclusion criteria: (1) clinical or pathological diagnosis of primary hepatocellular carcinoma; (2) liver function classification: Child-Pugh classification A or B, performance score (ECOG) 0-1 points; (3) no use of molecular targeted drugs or immunotherapy during treatment; (4) age range: 18-70 years. Exclusion criteria: (1) liver function classification: Child-Pugh classification $\mathrm{C}$, performance score (ECOG) $\geq 2$ points; (2) severe coagulation dysfunction and can not be corrected; (3) cachexia or extensive distant metastasis of the tumor; (4) complete occlusion of the portal vein and few collateral vessels; (5) renal insufficiency. This is a retrospective assessment of patients who were non-randomly treated with dexamethasone in TACE. There are two medical groups in our interventional therapy department. One of the medical groups routinely used dexamethasone in TACE to prevent the occurrence of post-embolization syndrome. Another medical group did not use dexamethasone in TACE. According to whether dexamethasone has been used in TACE, the patients were divided into two groups: TACE using lipiodol + chemotherapeutic emulsion group (TACE group, $\mathrm{N}=133$ ); TACE using lipiodol + dexamethasone + chemotherapeutic emulsion group (TACE + dexamethasone group, $\mathrm{N}=122$ ). The collected baseline data before TACE included gender, age, etiology of liver cirrhosis, ALT, AST, ALP, preoperative Child-Pugh classification of liver function, BCLC staging of tumor, whether opioid analgesics were used before operation, whether the patient was fasting before operation, previous history of vomiting, history of motion sickness, history of smoking, history of drinking, types of chemotherapeutic drugs used during TACE, and dosage of lipiodol used during TACE.

\section{Method}

After disinfection, draping, and local anesthesia of the puncture site with $2 \%$ lidocaine, the right femoral artery was punctured using the Seldinger technique and a $5 \mathrm{~F}$ vascular sheath was placed. The feeding artery of the tumor was identified by catheterization with a $5 \mathrm{~F}$ Yashino catheter to the celiac trunk and superior mesenteric artery for angiography. A $2.7 \mathrm{~F}$ microcatheter was then used to superselectively cannulate into the tumor feeding artery. Embolization was performed by slowly injecting an appropriate amount of lipiodol emulsion and supplementing embolization with 300-500 um gelatin sponge particles, and the embolization endpoint was stagnation of forward blood flow in the tumor feeding artery. Chemotherapeutic drugs used during surgery are divided into two types: (1) lobaplatin $50 \mathrm{mg}$; (2) epirubicin $30 \mathrm{mg}$. The amount of iodized oil used was 5-20 ml. Composition of lipiodol emulsion in TACE group: lipiodol+chemotherapeutic drugs; Composition of lipiodol emulsion in TACE + dexamethasone group: lipiodol+dexamethasone $10 \mathrm{mg}+$ chemotherapeutic drugs.

Materials and drugs used for TACE: 5F vascular sheath (TERUMO5F-10CM, Terumo, Japan), 0.035 inch (RFGA35153M, Terumo, Japan), 5F Yashino catheter (Terumo, Japan), 2.7F microcatheter (Terumo, Japan). Lobaplatin (GYZZ H20050308, Hainan Chang'an International Pharmaceutical Co., Ltd.), epirubicin (GYZZ H19990280, Zhejiang Hisun Pharmaceutical Co., Ltd.), Dexamethasone Sodium Phosphate for Injection (GYZZ H20080355, Chongqing Laimei Pharmaceutical Co., Ltd.).

\section{Outcome measures}

Primary study endpoint incidence of abdominal pain, fever, nausea and vomiting $0-72 \mathrm{~h}$ after TACE in both groups.

Secondary study endpoints incidence of infection after TACE in both groups.

Fever was defined as an axillary temperature $>37.3^{\circ} \mathrm{C}$. Nausea was defined as an uncomfortable feeling of wanting to vomit, but without contractile movements of the abdominal and diaphragmatic muscles. Vomiting is defined as contraction of the diaphragm, pectoral, and abdominal muscles, which may or may not be accompanied by vomiting of gastric contents. The evaluation criteria for nausea and vomiting were used: Common Terminology Criteria for Adverse Events (CTCAE 5.0) [11]. Infection includes positive blood cultures or liver abscess. 


\section{Statistical methods}

Statistical analysis was performed using SPSS software (Version 24.0, IBM, Armonk, New York). Number of cases (expressed as percentage) was used for enumeration data, and chi-square test was used for differences, including Pearson Chi-Square and Fisher's Exact Test. Measurement data were expressed as mean \pm standard deviation, and two independent samples $t$ test was used. $P<0.05$ was considered to indicate a statistically significant difference.

\section{Results}

\section{Basic information}

Preoperative enumeration data of TACE group and TACE + dexamethasone group: gender, preoperative Child-Pugh classification of liver function, etiology of liver cirrhosis, BCLC stage of tumor, previous history of vomiting, history of motion sickness, smoking history, drinking history, preoperative use of opioid analgesics, preoperative fasting (Table 1). Chi-square test was used between two groups with $P$ value $>0.05$ and no statistical difference.

Preoperative measurement data of TACE group and TACE + dexamethasone group: age, ALT, AST and ALP (Table 2). Comparisons between two groups were performed using the $t$ test with a $P$ value $>0.05$ and no statistical difference.

Intraoperative enumeration data of TACE group and TACE + dexamethasone group: types of chemotherapeutic drugs used in TACE and dosage of lipiodol used in TACE (Table 3). Chi-square test was used for comparison between two groups with $P$ value $>0.05$ and no statistical difference.

\section{Incidence of post-embolization syndrome after TACE (Table 4)}

Incidence of post-embolization syndrome after TACE (TACE group vs TACE + dexamethasone group): abdominal pain, $74(55.6 \%)$ versus $44(36.1 \%), P$ value 0.002 ; fever, $50(37.6 \%)$ versus $16(13.1 \%), P$ value 0.000 ; nausea, $81(60.9 \%)$ versus $50(41.0 \%), P$ value $0.001 / 0.002$; vomiting, $64(48.1 \%)$ versus $26(21.3 \%), P$ value 0.000 .

Chi-square test was used for comparison between the two groups, including Pearson Chi-Square and Fisher's Exact Test, with $P$ value $<0.05$, which was statistically different.

\section{Incidence of infection after TACE (Table 5)}

Incidence of infection after TACE (TACE group vs TACE + dexamethasone group): 2 (1.5\%) versus 3 (2.5\%), $P$ value $0.583 / 0.672$.
Chi-square test was used for comparison between the two groups, including Pearson Chi-Square and Fisher's Exact Test, with $P$ value $>0.05$ and no statistical difference.

\section{Discussion}

TACE is one of the main means of treating hepatocellular carcinoma [37]. TACE was shown to improve median survival from 16 to 20 months. TACE is effective in the treatment of hepatocellular carcinoma and plays a very important role in the treatment of hepatocellular carcinoma. The most common side effects after TACE are post-embolization syndrome, including abdominal pain, fever, nausea and vomiting. More and more attention has been paid to post-embolization syndrome after TACE by doctors and patients. According to the existing studies on the efficacy and safety of TACE, the incidence rate of post-embolization syndrome after TACE is about $47.7 \%$ [6].

The causes of post-embolization syndrome after TACE are [12-14]: (1) the trauma, ischemia, and hypoxia of the operation lead to pain; the aseptic inflammation caused by ischemia and hypoxia induces the release of a variety of transmitters, leading to fever, nausea and vomiting; (2) the intraoperative use of chemotherapeutic drugs, through the blood circulation, stimulates the chemoreceptors of the gastrointestinal tract; in particular, chemotherapeutic drugs are often injected through the celiac trunk or superior mesenteric artery branches during TACE, while the celiac trunk or superior mesenteric artery already has vascular branches that directly supply the gastrointestinal tract; the epirubicin and platinum used during TACE are chemotherapeutic drugs with moderate to high emetic risk; (3) the organs involved in TACE are the liver and gallbladder, and hepatic arterial embolization will lead to hepatobiliary ischemia; Similar to the causes of PONV, hepatobiliary surgery is more likely to cause postoperative nausea and vomiting than other surgeries; (4) the stress during TACE may cause the release of dopamine, epinephrine and other transmitters, resulting in nausea and vomiting; (5) patient factors, such as young women, no smoking history, history of PONV, history of motion sickness; (6) tumor ischemic necrosis after TACE, metabolism and absorption of necrotic substances, and release of inflammatory transmitters, resulting in pain and fever. Severe post-embolization syndrome will increase the suffering of patients, aggravate the physical and psychological burden of patients, and reduce the compliance of patients with treatment. At the same time, it prolongs the patient's hospital stay and increases the patient's medical costs $[6,15]$.

Post-embolization syndrome after TACE is mainly controlled by symptomatic treatment. Studies have 
Table 1 General information of the patients

\begin{tabular}{|c|c|c|c|c|}
\hline & \multicolumn{2}{|l|}{ Group } & \multicolumn{2}{|c|}{ Chi-square test ( $P$ value) } \\
\hline & TACE $(N=133)$ & TACE + Dexamethasone $(\mathrm{N}=122)$ & Pearson chi-square & $\begin{array}{l}\text { Fisher's } \\
\text { exact test }\end{array}$ \\
\hline \multicolumn{5}{|l|}{ Gender } \\
\hline \multicolumn{5}{|l|}{ Female } \\
\hline Count (\%) & $68(51.1 \%)$ & $52(42.6 \%)$ & 0.174 & 0.209 \\
\hline \multicolumn{5}{|l|}{ Male } \\
\hline Count (\%) & 65 (48.9\%) & $70(57.4 \%)$ & & \\
\hline \multicolumn{5}{|c|}{ Child-Pugh classification of liver function } \\
\hline \multicolumn{5}{|c|}{ A } \\
\hline Count (\%) & $95(71.4 \%)$ & $85(69.7 \%)$ & 0.758 & 0.784 \\
\hline \multicolumn{5}{|l|}{ B } \\
\hline Count (\%) & $38(28.6 \%)$ & $37(30.3 \%)$ & & \\
\hline \multicolumn{5}{|c|}{ Etiology of cirrhosis } \\
\hline \multicolumn{5}{|c|}{ Hepatitis B } \\
\hline Count (\%) & $120(90.2 \%)$ & $111(91.0 \%)$ & 0.836 & 1.000 \\
\hline \multicolumn{5}{|l|}{ Hepatitis C } \\
\hline Count (\%) & $13(9.8 \%)$ & $11(9.0 \%)$ & & \\
\hline \multicolumn{5}{|l|}{ BCLC staging } \\
\hline \multicolumn{5}{|l|}{ A } \\
\hline Count (\%) & $14(10.5 \%)$ & $12(9.8 \%)$ & 0.682 & \\
\hline \multicolumn{5}{|l|}{ B } \\
\hline Count (\%) & $80(60.2 \%)$ & $68(55.7 \%)$ & & \\
\hline \multicolumn{5}{|l|}{ C } \\
\hline Count (\%) & $39(29.3 \%)$ & $42(34.4 \%)$ & & \\
\hline \multicolumn{5}{|c|}{ History of vomiting } \\
\hline \multicolumn{5}{|c|}{ No } \\
\hline Count (\%) & $108(81.2 \%)$ & 95 (77.9\%) & 0.509 & 0.537 \\
\hline \multicolumn{5}{|l|}{ Yes } \\
\hline Count (\%) & 25 (18.8\%) & $27(22.1 \%)$ & & \\
\hline \multicolumn{5}{|c|}{ Motion sickness } \\
\hline \multicolumn{5}{|l|}{ No } \\
\hline Count (\%) & $100(75.2 \%)$ & 99 (81.1\%) & 0.251 & 0.290 \\
\hline \multicolumn{5}{|l|}{ Yes } \\
\hline Count (\%) & $33(24.8 \%)$ & 23 (18.9\%) & & \\
\hline \multicolumn{5}{|c|}{ Smoking history } \\
\hline No & & & & \\
\hline Count (\%) & 105 (78.9\%) & 100 (82.0\%) & 0.544 & 0.636 \\
\hline Yes & & & & \\
\hline Count (\%) & $28(21.1 \%)$ & 22 (18.0\%) & & \\
\hline Alcohol history & & & & \\
\hline No & & & & \\
\hline Count (\%) & 110 (82.7\%) & $103(84.4 \%)$ & 0.712 & 0.738 \\
\hline Yes & & & & \\
\hline Count (\%) & $23(17.3 \%)$ & $19(15.6 \%)$ & & \\
\hline History of anal & & & & \\
\hline No & & & & \\
\hline Count (\%) & 93 (69.9\%) & $90(73.8 \%)$ & 0.496 & 0.578 \\
\hline Yes & & & & \\
\hline Count (\%) & $40(30.1 \%)$ & $32(26.2 \%)$ & & \\
\hline
\end{tabular}


Table 1 (continued)

\begin{tabular}{|c|c|c|c|c|}
\hline & \multicolumn{2}{|l|}{ Group } & \multicolumn{2}{|c|}{ Chi-square test ( $P$ value) } \\
\hline & TACE $(\mathrm{N}=133)$ & TACE + Dexamethasone $(\mathrm{N}=122)$ & Pearson chi-square & $\begin{array}{l}\text { Fisher's } \\
\text { exact test }\end{array}$ \\
\hline \multicolumn{5}{|c|}{ Preoperative fasting } \\
\hline \multicolumn{5}{|c|}{ No } \\
\hline Count (\%) & 65 (48.9\%) & $69(56.6 \%)$ & 0.220 & 0.259 \\
\hline \multicolumn{5}{|l|}{ Yes } \\
\hline Count (\%) & $68(51.1 \%)$ & $53(43.4 \%)$ & & \\
\hline
\end{tabular}

Table 2 Patient's age and liver function before TACE

\begin{tabular}{llll}
\hline Group & Mean & Std. deviation & $\boldsymbol{t}$ test $(\boldsymbol{P}$ value $)$ \\
\hline Age & & & \\
TACE & 47.3 & 11.6 & 0.331 \\
TACE + dexamethasone & 48.8 & 12.5 & \\
ALT & & & \\
TACE & 42.6 & 17.8 & 0.155 \\
TACE + dexamethasone & 47.1 & 19.0 & \\
AST & & & \\
TACE & 41.3 & 17.8 & 0.093 \\
TACE + dexamethasone & 45.4 & 17.7 & \\
ALP & & & 0.389 \\
TACE & 90.7 & 29.1 & \\
TACE + dexamethasone & 93.6 & 23.7 &
\end{tabular}

confirmed that 5-HT3 receptor antagonists can effectively control the occurrence of nausea and vomiting after TACE. The application of analgesic drugs after TACE can reduce the occurrence of postoperative abdominal pain in patients. However, because most patients with primary hepatocellular carcinoma have a background of cirrhosis, they may have liver dysfunction before TACE. After TACE, the use of embolic agents and chemotherapeutic drugs may cause short-term liver function damage. At this time, if multiple drugs are used concomitantly to control post-embolization syndrome, the burden of liver metabolism will be increased, resulting in aggravated liver function damage. It is well-known that dexamethasone, as a steroid preparation, has anti-infective and immunosuppressive effects. Dexamethasone, like other glucocorticoids, has pharmacological effects such as inhibition of immunity, anti-shock and enhancement of stress response, so it is widely used in the treatment of a variety of diseases. It has (1) anti-inflammatory effect: it can reduce and prevent the tissue response to inflammation, thereby reducing the performance of inflammation. Hormones inhibit the accumulation of inflammatory cells, including macrophages and leukocytes, at sites of inflammation, and inhibit phagocytosis, release of

Table 3 Application of chemotherapeutic drugs and lipiodol in TACE

\begin{tabular}{|c|c|c|c|c|}
\hline & \multicolumn{2}{|l|}{ Group } & \multicolumn{2}{|c|}{ Chi-square test ( $P$ value) } \\
\hline & TACE $(N=133)$ & TACE + dexamethasone $(\mathrm{N}=122)$ & Pearson chi-square & $\begin{array}{l}\text { Fisher's } \\
\text { exact test }\end{array}$ \\
\hline \multicolumn{5}{|c|}{ Intraoperative chemotherapeutic agents } \\
\hline \multicolumn{5}{|c|}{ Lobaplatin } \\
\hline Count (\%) & $68(51.1 \%)$ & $63(51.6 \%)$ & 0.935 & 1.000 \\
\hline \multicolumn{5}{|l|}{ Epirubicin } \\
\hline Count (\%) & 65 (48.9\%) & $59(48.4 \%)$ & & \\
\hline \multicolumn{5}{|c|}{ Intraoperative lipiodol dose } \\
\hline \multicolumn{5}{|c|}{$<5 \mathrm{ml}$} \\
\hline Count (\%) & $41(30.8 \%)$ & $39(32.0 \%)$ & 0.897 & \\
\hline \multicolumn{5}{|l|}{$5-10 \mathrm{ml}$} \\
\hline Count (\%) & $55(41.4 \%)$ & $47(38.5 \%)$ & & \\
\hline \multicolumn{5}{|l|}{$10 \mathrm{ml}$} \\
\hline Count (\%) & $37(27.8 \%)$ & $36(29.5 \%)$ & & \\
\hline
\end{tabular}


Table 4 Incidence of Post embolism syndrome after TACE

\begin{tabular}{|c|c|c|c|c|}
\hline & \multicolumn{2}{|l|}{ Group } & \multicolumn{2}{|c|}{ Chi-square test ( $P$ value) } \\
\hline & TACE $(N=133)$ & $\mathrm{TACE}+$ Dexamethasone $(\mathrm{N}=122)$ & Pearson Chi-Square & $\begin{array}{l}\text { Fisher's } \\
\text { exact tes }\end{array}$ \\
\hline \multicolumn{5}{|c|}{ Abdominal pain } \\
\hline \multicolumn{5}{|l|}{ No } \\
\hline Count (\%) & $59(44.4 \%)$ & $78(63.9 \%)$ & 0.002 & 0.002 \\
\hline \multicolumn{5}{|l|}{ Yes } \\
\hline Count (\%) & $74(55.6 \%)$ & $44(36.1 \%)$ & & \\
\hline \multicolumn{5}{|l|}{ Fever } \\
\hline \multicolumn{5}{|l|}{ No } \\
\hline Count (\%) & $83(62.4 \%)$ & $106(86.9 \%)$ & 0.000 & 0.000 \\
\hline \multicolumn{5}{|l|}{ Yes } \\
\hline Count (\%) & $50(37.6 \%)$ & $16(13.1 \%)$ & & \\
\hline \multicolumn{5}{|l|}{ Nausea } \\
\hline \multicolumn{5}{|l|}{ No } \\
\hline Count (\%) & $52(39.1 \%)$ & $72(59.0 \%)$ & 0.001 & 0.002 \\
\hline \multicolumn{5}{|l|}{ Yes } \\
\hline Count (\%) & $81(60.9 \%)$ & $50(41.0 \%)$ & & \\
\hline \multicolumn{5}{|l|}{ Vomiting } \\
\hline \multicolumn{5}{|l|}{ No } \\
\hline Count (\%) & $69(51.9 \%)$ & $96(78.7 \%)$ & 0.000 & 0.000 \\
\hline \multicolumn{5}{|l|}{ Yes } \\
\hline Count (\%) & $64(48.1 \%)$ & $26(21.3 \%)$ & & \\
\hline
\end{tabular}

Table 5 Incidence of infection after TACE

\begin{tabular}{|c|c|c|c|c|}
\hline & \multicolumn{2}{|l|}{ Group } & \multicolumn{2}{|c|}{ Chi-square test ( $P$ value) } \\
\hline & TACE $(N=133)$ & TACE + Dexamethasone $(\mathrm{N}=122)$ & Pearson chi-square & $\begin{array}{l}\text { Fisher's } \\
\text { exact } \\
\text { test }\end{array}$ \\
\hline \multicolumn{5}{|l|}{ Infection } \\
\hline \multicolumn{5}{|l|}{ No } \\
\hline Count (\%) & $131(98.5 \%)$ & $119(97.5 \%)$ & 0.583 & 0.672 \\
\hline \multicolumn{5}{|l|}{ Yes } \\
\hline Count (\%) & $2(1.5 \%)$ & $3(2.5 \%)$ & & \\
\hline
\end{tabular}

lysosomal enzymes, and synthesis and release of inflammatory chemical mediators. (2) Immunosuppressive effects: including preventing or inhibiting cell-mediated immune responses, delayed allergic reactions, reducing the number of $\mathrm{T}$ lymphocytes, monocytes, and eosinophils, reducing the binding ability of immunoglobulins to cell surface receptors, and inhibiting the synthesis and release of interleukins, thereby reducing the transformation of $\mathrm{T}$ lymphocytes into lymphoblasts, and reducing the expansion of the primary immune response. It can reduce the passage of immune complexes through the basement membrane, and can reduce the concentration of complement components and immunoglobulin.
Dexamethasone has been shown to reduce the incidence of side effects induced by emetic chemotherapy. Dexamethasone is targeted at glucocorticoid receptors, which play a very important role in inflammation and immune response by inducing apoptosis of immune cells and inhibiting the release of inflammatory transmitters. Studies have shown that dexamethasone has a membrane-stabilizing effect, which can not only maintain the integrity of lysosomal membranes, but also regulate vascular permeability by strengthening cell-cell contact [16]. Dexamethasone plays a very important role in regulating systemic and local inflammatory responses due to its powerful role in stabilizing the endothelium. 
Many studies have shown [17] that dexamethasone plays a very effective role in preventing PONV and CINV. Liu et al. [18] reported that dexamethasone could significantly reduce the incidence of POV in postoperative and few adverse effects were reported. Bustos et al. [19] found that dexamethasone is a safe adjunct to perioperative protocol that may reduce nausea, thus improving patient satisfaction, and there is an associated reduction in length of stay that may reduce cost of hospitalization. The findings of Moheimani et al. [20] showed that a single preoperative dose of i.v. dexamethasone reduces PONV. Dexamethasone also plays a very important role in the prevention and treatment of CINV [21]. Isoda et al. [22] found that the three-antiemetic regimen consisting of palonosetron, aprepitant, and dexamethasone was safe and effective for controlling CINV. The study of Lorusso et al. [23] showed that a single dose of palonosetron and dexamethasone was able to prevent CINV in most patients. Celio et al. [24] demonstrated that palonosetron plus 1-day dexamethasone regimen provides a valid treatment option for prevention of CINV. Studies have shown that dexamethasone relieves postoperative pain after surgery and also prolongs the duration of postoperative analgesia $[25,26]$. The article by Tenghui Zhang et al. [27] reported that a single, intravenous 8-mg dose of dexamethasone upon induction of anesthesia reduced the intensity of postoperative pain, and shortened the postoperative length of stay. Klag et al. [28] reported that dexamethasone decreases opioid requirements in the first $24 \mathrm{~h}$ following surgery, provides improved pain control, and decreases antiemetic use, Dexamethasone is an important multimodal adjunct for controlling pain and postoperative nausea and vomiting. Perioperative dexamethasone is effective to reduce the pain, nausea and vomiting after thyroid surgery, which was reported by Cheng et al. [29]. Some studies have reported [30] not only does Dexamethasone reduce the incidence of PONV but also decreases postoperative pain. Because of this, we speculated that dexamethasone may also have very good safety and efficacy in controlling post-embolization syndrome after TACE.

In recent years, some clinical trials have also confirmed the utility and safety of dexamethasone in preventing the adverse effects of TACE [31-33]. Ogasawara et al. [34] found that the dexamethasone regimen was more effective than the control regimen at preventing TACEinduced fever, anorexia, and nausea/vomiting in patients with HCC. Intra-arterial lidocaine, steroids, and a 5-HT3 receptor antagonist are found to offer potential benefit in the management of PES symptoms by Blackburn et al. [35]. Ogasawara et al. [34] showed that dexamethasone could reduce the incidence of post-embolization syndrome after TACE and promote the recovery of patients.
Meanwhile, dexamethasone was also very safe in patients with diabetes and impaired glucose tolerance. In the study, it was found that for patients with hepatitis B background, the use of dexamethasone also did not lead to the activation of hepatitis $B$. The results of this study showed that: Incidence of post-embolization syndrome after TACE (TACE group vs TACE + dexamethasone group): abdominal pain, $55.6 \%$ versus $36.1 \%(P<0.05)$; fever, $37.6 \%$ versus $13.1 \%(P<0.05)$; nausea, $60.9 \%$ versus $41.0 \%$ $(P<0.05)$; vomiting, $48.1 \%$ versus $21.3 \%(P<0.05)$. All were statistically different. The incidence of post-embolization syndrome in TACE + dexamethasone group was significantly lower than that in TACE group.

Since dexamethasone can inhibit the immune function of the body and has no antibacterial effect, its clinical use can induce infection or aggravate infection, which can make the potential foci of infection in the body spread or the quiescent foci of infection resurface, especially those with decreased original resistance. Since patients often feel good about themselves after using dexamethasone and mask the symptoms of infection development, the use of dexamethasone in TACE has the potential to increase the risk of infection in patients. However, existing studies [36] showed that the use of dexamethasone in the treatment of post-embolization syndrome after TACE did not increase the incidence of infection in patients, and the use of dexamethasone in TACE was safe. In this study, the incidence of infection after TACE: 2 cases in TACE group, with an incidence rate of $1.5 \% .3$ cases in the TACE + dexamethasone group, with an incidence rate of $2.5 \%$. $(P>0.05)$ There was no significant statistical difference, which was consistent with the results of other studies. However, in other studies, the administration mode of dexamethasone was intravenous bolus injection. In this study, the administration mode of dexamethasone was emulsion mixed with lipiodol. The microcatheter was used for injection into the tumor area, which was also safe and effective.

\section{Conclusions}

There are multiple causes for post-embolization syndrome after TACE, including surgical trauma, ischemia and hypoxia of tumor tissue, aseptic inflammation, intraoperative use of chemotherapeutic drugs, ischemia of liver and bile duct, stress during TACE, patient factors (such as young women, no smoking history, history of PONV, history of motion sickness), absorption and metabolism of necrotic substances after tumor embolization. In TACE, the lipiodol + dexamethasone emulsion can significantly reduce the incidence rate of post-embolization syndrome after TACE, with exact effect and high safety. The preventive intervention in TACE can reduce the psychological and physical burden of patients, reduce 
the perioperative risk and improve the treatment compliance of patients. The shortcomings of this study are that the data are from a single-center retrospective study, and the sample size is limited. The practice differences of the two medical groups may affect the observed results. A multi-center, large-sample, prospective study is feasible at a later stage to provide more help for clinical work. At the same time, in this study, the use of dexamethasone was to inject lipiodol + dexamethasone emulsion during embolization, and relevant studies could be designed at a later stage to investigate the efficacy analysis of lipiodol + dexamethasone emulsion embolization and conventional intravenous bolus injection of dexamethasone.

\section{Acknowledgements}

Thank Pro. Guohui Liu for his help in English writing. Thank Dr. Wei Wang for his help in data collection. Thank Dr. Kang Zhang for his help in reference. Thank you for all those who offer help and support in this research.

\begin{abstract}
Authors' contributions
HL have made substantial contributions to the conception and design of the work, and the acquisition, analysis of data, as well as manuscript writing. CZ have made contributions to the design of the work. BL have made contributions to the acquisition, analysis of data. BX have made contributions to analysis, interpretation of data, and manuscript writing. All authors have agreed both to be personally accountable for the author's own contributions and to ensure that questions related to the accuracy or integrity of any part of the work. $\mathrm{HL}$ is the first author. CZ is corresponding author, and responsible for ensuring that all listed authors have approved the manuscript before submission. All authors read and approved the final manuscript.
\end{abstract}

\section{Funding}

No funding is provided in this study.

\section{Availability of data and materials}

The datasets used and analysed during the current study are available from the corresponding author on reasonable request.

\section{Declarations}

\section{Ethics approval and consent to participate}

The medical ethics committee of our college (Wuhan Union Hospital, Tongji Medical College, Huazhong University of science and technology, Wuhan, Hubei Province) approved the retrospective study. As the study was retrospective, it did not affect the diagnosis and treatment of patients. The medical ethics committee of our college gave up the written informed consent. Although the ethics committee gave up the written consent, for the safety and rationality of the research, all participants signed informed consent for the study. Of course, all the patients signed the informed consent before the operation. During follow-up, we informed patients about the study and they agreed to use their data. We confirm that all methods were performed in accordance with the relevant guidelines and Declaration of Helsinki.

\section{Consent for publication}

All participants' information, images and inspection results are agreed to be published and have obtained written consent. The details, images will be freely available on the internet and may be seen by the general public. The consent form is available if requested. These patients have not been reported in any other submission by anyone.

\section{Competing interests}

We declare that we have no financial and personal relationships with other people or organizations that can inappropriately influence our work, there is no professional or other personal interest of any nature or kind in any product, service and company that could be construed as influencing the position presented in this manuscript.

\section{Author details}

${ }^{1}$ Department of Radiology, Wuhan Union Hospital, Tongji Medical College, Huazhong University of Science and Technology, Jiefang Avenue \#1277, Wuhan 430022, China. ${ }^{2}$ Hubei Province Key Laboratory of Molecular Imaging, Wuhan 430022, China.

Received: 22 April 2021 Accepted: 3 June 2021

Published online: 11 June 2021

\section{References}

1. Hartke J, Johnson M, Ghabril M. The diagnosis and treatment of hepatocellular carcinoma. Semin Diagn Pathol. 2017;34(2):153-9. https://doi.org/ 10.1053/j.semdp.2016.12.011 (Epub 2016 Dec 20 PMID: 28108047).

2. Clark T, Maximin S, Meier J, et al. Hepatocellular carcinoma: review of epidemiology, screening, imaging diagnosis, response assessment, and treatment. Curr Probl Diagn Radiol. 2015;44(6):479-86. https://doi.org/10. 1067/j.cpradiol.2015.04.004 (Epub 2015 Apr 16 PMID: 25979220).

3. Budny A, Kozłowski P, Kamińska M, et al. Epidemiologia i czynniki ryzyka rozwoju raka wątrobowokomórkowego [Epidemiology and risk factors of hepatocellular carcinoma]. Pol Merkur Lekarski. 2017:43(255):133-9 (Polish. PMID: 28987047).

4. Reuter SR. The current status of angiography in the evaluation of cancer patients. Cancer. 1976;37(1 suppl):532-41. https://doi.org/10.1002/10970142(197601)37:1 +\%3c532::aid-cncr2820370718\%3e3.0.co;2-k (PMID: 942883).

5. Friedman MA, Volberding PA, Cassidy MJ, et al. Therapy for hepatocellular cancer with intrahepatic arterial adriamycin and 5-fluorouracil combined with whole-liver irradiation: a Northern California Oncology Group Study. Cancer Treat Rep. 1979;63(11-12):1885-8 (PMID: 230895).

6. Lencioni R, de Baere T, Soulen MC, et al. Lipiodol transarterial chemoembolization for hepatocellular carcinoma: a systematic review of efficacy and safety data. Hepatology. 2016;64(1):106-16. https://doi.org/10.1002/ hep.28453 (Epub 2016 Mar 7 PMID: 26765068).

7. Casadaban LC, Minocha J, Bui JT, et al. Conventional ethiodized oil transarterial chemoembolization for treatment of hepatocellular carcinoma: contemporary single-center review of clinical outcomes. AJR Am J Roentgenol. 2016;206(3):645-54. https://doi.org/10.2214/AJR.15.14758 (PMID: 26901023).

8. Bessar AA, Farag A, Abdel Monem SM, et al. Transarterial chemoembolisation in patients with hepatocellular carcinoma: low-dose doxorubicin reduces post-embolisation syndrome without affecting survival-prospective interventional study. Eur Radiol Exp. 2021;5(1):10. https://doi.org/10. 1186/s41747-021-00204-6.PMID:33649930;PMCID:PMC7921261.

9. Gjoreski A, Jovanoska I, Risteski F, et al. Single-center randomized trial comparing conventional chemoembolization versus doxorubicin-loaded polyethylene glycol microspheres for early- and intermediate-stage hepatocellular carcinoma. Eur J Cancer Prev. 2021;30(3):258-66. https:// doi.org/10.1097/CEJ.0000000000000623 (PMID: 33038087).

10. Khalaf MH, Sundaram V, AbdelRazek Mohammed MA, et al. A predictive model for postembolization syndrome after transarterial hepatic chemoembolization of hepatocellular carcinoma. Radiology. 2019;290(1):25461. https://doi.org/10.1148/radiol.2018180257 (Epub 2018 Oct 9 PMID: 30299233).

11. Fairchild AT, Tanksley JP, Tenenbaum JD, et al. Interrater reliability in toxicity identification: limitations of current standards. Int J Radiat Oncol Biol Phys. 2020;107(5):996-1000. https://doi.org/10.1016/j.jijobp.2020.04.040 (Epub 2020 May 3 PMID: 32371073).

12. Dhand S, Gupta R. Hepatic transcatheter arterial chemoembolization complicated by postembolization syndrome. Semin Interv Radiol. 2011;28(2):207-11. https://doi.org/10.1055/s-0031-1280666.PMID:22654 264:PMCID:PMC3193324.

13. Leung DA, Goin JE, Sickles C, et al. Determinants of postembolization syndrome after hepatic chemoembolization. J Vasc Interv Radiol. 2001;12(3):321-6. https://doi.org/10.1016/s1051-0443(07)61911-3 (PMID: 11287509)

14. Wang SY, Zhu WH, Vargulick S, et al. Nausea and vomiting after transcatheter arterial chemoembolization for hepatocellular carcinoma: incidence and risk factor analysis. Asian Pac J Cancer Prev. 2013;14(10):5995-6000. https://doi.org/10.7314/apjcp.2013.14.10.5995 (PMID: 24289614). 
15. Kuwaki K, Nouso K, Miyashita M, et al. The efficacy and safety of steroids for preventing postembolization syndrome after transcatheter arterial chemoembolization of hepatocellular carcinoma. Acta Med Okayama. 2019;73(4):333-9. https://doi.org/10.18926/AMO/56935 (PMID: 31439956).

16. Oberleithner H, Riethmüller C, Ludwig T, et al. Differential action of steroid hormones on human endothelium. J Cell Sci. 2006;119(Pt 9):1926-32. https://doi.org/10.1242/jcs.02886.Erratum.In:JCellSci.2007Jul15;120(Pt14): 2467 (PMID: 16636077).

17. Weibel S, Rücker G, Eberhart LH, et al. Drugs for preventing postoperative nausea and vomiting in adults after general anaesthesia: a network metaanalysis. Cochrane Database Syst Rev. 2020;10:CD012859. https://doi.org/ 10.1002/14651858.CD012859.pub2 (PMID: 33075160).

18. Liu J, Li H, Zhang J, et al. Dexamethasone or combined with others for postoperative nausea and vomiting in children: a systematic review. Asian J Surg. 2020;43(9):873-9. https://doi.org/10.1016/j.asjsur.2019.11. 012 (Epub 2020 Jan 18 PMID: 31964583).

19. Bustos FP, Coobs BR, Moskal JT. A retrospective analysis of the use of intravenous dexamethasone for postoperative nausea and vomiting in total joint replacement. Arthroplast Today. 2019;5(2):211-5. https://doi.org/10. 1016/j.artd.2019.01.007.PMID:31286046;PMCID:PMC6588720.

20. Moheimani H, Yaseri M. Dexamethasone reduces postoperative nausea in pediatric upper endoscopy with deep sedation: a randomized controlled trial. J Pediatr Gastroenterol Nutr. 2019;69(3):281-6. https://doi.org/10. 1097/MPG.0000000000002398 (PMID: 31124887)

21. Mahrous MA, El-Azab GA, Tawfik HA. Evaluation of clinical outcomes and efficacy of palonosetron and granisetron in combination with dexamethasone in Egyptian patients receiving highly emetogenic chemotherapy. Cancer Chemother Pharmacol. 2021. https://doi.org/10.1007/ s00280-021-04257-7 (PMID: 33835230).

22. Isoda A, Saito R, Komatsu F, et al. Palonosetron, aprepitant, and dexamethasone for prevention of nausea and vomiting after high-dose melphalan in autologous transplantation for multiple myeloma: a phase II study. Int J Hematol. 2017;105(4):478-84. https://doi.org/10.1007/s12185016-2152-6 (Epub 2016 Nov 21 PMID: 27873176).

23. Lorusso V, Giampaglia M, Petrucelli L, et al. Antiemetic efficacy of singledose palonosetron and dexamethasone in patients receiving multiple cycles of multiple day-based chemotherapy. Support Care Cancer. 2012;20(12):3241-6. https://doi.org/10.1007/s00520-012-1469-9 (Epub 2012 Apr 26. PMID: 22534864; PMCID: PMC3480578)

24. Celio L, Denaro A, Agustoni F, et al. Palonosetron plus 1-day dexamethasone for the prevention of nausea and vomiting due to moderately emetogenic chemotherapy: effect of established risk factors on treatment outcome in a phase III trial. J Support Oncol. 2012;10(2):65-71. https://doi.org/10.1016/j.suponc.2011.06.007 (Epub 2011 Sep 23 PMID: 22005217)

25. Kim BG, Lee W, Song JH, et al. Effect of intravenous dexamethasone on the duration of postoperative analgesia for popliteal sciatic nerve block: a randomized, double-blind, placebo-controlled study. Korean J Anesthesiol. 2021. https://doi.org/10.4097/kja.20640 (PMID: 33784802).

26. Kubala ME, Turner M, Gardner JR, et al. Impact of oral steroids on tonsillectomy postoperative complications and pain. Ear Nose Throat J. 2021. https://doi.org/10.1177/01455613211000832 (PMID: 33734886).
27. Zhang T, Xu Y, Yao Y, et al. Randomized controlled trial: perioperative dexamethasone reduces excessive postoperative inflammatory response and ileus after surgery for inflammatory bowel disease. Inflamm Bowel Dis. 2021. https://doi.org/10.1093/ibd/izab065 (PMID: 33749741).

28. Klag EA, Kuhlmann NA, Tramer JS, et al. Dexamethasone decreases postoperative opioid and antiemetic use in shoulder arthroplasty patients: a prospective, randomized controlled trial. J Shoulder Elbow Surg. 2021. https://doi.org/10.1016/j.jse.2020.12.005 (PMID: 33486058).

29. Cheng $L$, Le $Y$, Yang $H$, et al. The effect of dexamethasone on pain control after thyroid surgery: a meta-analysis of randomized controlled trials. Eur Arch Otorhinolaryngol. 2020. https://doi.org/10.1007/s00405-020-062458 (PMID: 32804272).

30. Xu L, Xie X, Gu X. Dexamethasone for preventing postoperative nausea and vomiting after mastectomy. Medicine (Baltimore). 2020;99(30):e21417. https://doi.org/10.1097/MD.0000000000021417. PMID:32791759;PMCID:PMC7387045.

31. Sakamoto T, Saito Y, Kobayashi M, et al. Effect of palonosetron and dexamethasone administration on the prevention of gastrointestinal symptoms in hepatic arterial chemoembolization with epirubicin. Support Care Cancer. 2020;28(7):3251-7. https://doi.org/10.1007/s00520-01905178-1 (Epub 2019 Nov 16 PMID: 31732854).

32. Kogut MJ, Chewning RH, Harris WP, et al. Postembolization syndrome after hepatic transarterial chemoembolization: effect of prophylactic steroids on postprocedure medication requirements. J Vasc Interv Radiol. 2013;24(3):326-31. https://doi.org/10.1016/j.jvir.2012.11.019 (Epub 2013 Feb 4 PMID: 23380736).

33. Hesketh PJ, Kris MG, Basch E, et al. Antiemetics: American society of clinical oncology clinical practice guideline update. J Clin Oncol. 2017;35(28):3240-61. https://doi.org/10.1200/JCO.2017.74.4789 (Epub 2017 Jul 31 PMID: 28759346).

34. Ogasawara S, Chiba T, Ooka Y, et al. A randomized placebo-controlled trial of prophylactic dexamethasone for transcatheter arterial chemoembolization. Hepatology. 2018;67(2):575-85. https://doi.org/10.1002/hep. 29403 (Epub 2017 Dec 23 PMID: 28746788).

35. Blackburn H, West S. Management of postembolization syndrome following hepatic transarterial chemoembolization for primary or metastatic liver cancer. Cancer Nurs. 2016;39(5):E1-18. https://doi.org/10.1097/NCC. 0000000000000302 (PMID: 26484962).

36. Chang L, Wang W, Jiang $N$, et al. Dexamethasone prevents TACEinduced adverse events: a meta-analysis. Medicine (Baltimore). 2020;99(47):e23191. https://doi.org/10.1097/MD.0000000000023191. PMID:33217828;PMCID:PMC7676579.

37. Young M, John S. Hepatic Chemoembolization. In: StatPearls [Internet]. Treasure Island (FL): StatPearls Publishing; 2021 Jan-. PMID: 29939599.

\section{Publisher's Note}

Springer Nature remains neutral with regard to jurisdictional claims in published maps and institutional affiliations.

Ready to submit your research? Choose BMC and benefit from:

- fast, convenient online submission

- thorough peer review by experienced researchers in your field

- rapid publication on acceptance

- support for research data, including large and complex data types

- gold Open Access which fosters wider collaboration and increased citations

- maximum visibility for your research: over 100M website views per year

At BMC, research is always in progress.

Learn more biomedcentral.com/submissions 